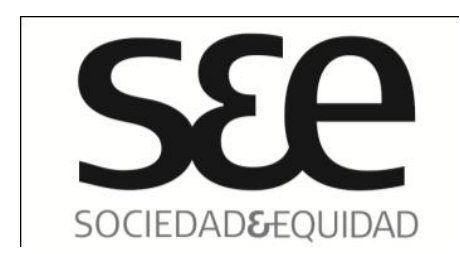

\title{
Las Marcas del Miedo Urbano
}

\author{
Nombre: Marcela Mansilla \\ Universidad: Universidad Alberto Hurtado \\ Ciudad: $\quad$ Santiago \\ País: $\quad$ Chile \\ Correo: $\quad$ mansilla.marcela088@gmail.com
}

\section{Resumen}

El artículo desarrolla la relación entre delincuencia e inseguridad y cómo, en la configuración de dichos términos, surge el estigma y sus consecuencias. Conceptos como anomia y estigma de Merton y Goffman respectivamente, resultan claves para el análisis de la estructura social en la cual se construye el estigma. La metodología utilizada fue un estudio de caso donde fueron entrevistados habitantes de las comunas de Las Condes y Peñalolén, para obtener sus percepciones respecto a delincuencia e inseguridad. Tomando como referencia su contexto territorial y sociocultural, pudieron ser analizadas y posteriormente objetivadas, las formas en que se manifiesta el estigma entre normales y desacreditados, buscando de este modo visualizar nuevas perspectivas hacia las problemática causadas por el estigma.

\section{Palabras claves}

Delincuencia, inseguridad, estigma, anomia.

\section{The marks of urban fear}

This paper develops the relationship between delinquency and insecurity and how, in the configuration of these terms, there is the stigma and its consequences. Concepts such as anomie and stigma of Merton and Goffman, respectively, are keys to the analysis of social structure in which the stigma is constructed. The methodology used was a case study where were interviewed residents of the area of Las Condes and Peñalolen to obtain their perceptions of delinquency and insecurity. Reference to their territorial and socio-cultural context, could be analyzed and then objectified, the ways in which stigma is expressed between normal and discredited.

\section{Keywords}

Crime, insecurity, stigma, anomie.

$\left({ }^{\bullet}\right.$ ) La autora es Bachiller en Ciencias Sociales y Licenciada en Sociología 


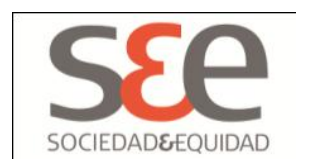

\section{Introducción}

Las últimas décadas han sido cruciales en el desarrollo social y económico de los países de Latinoamérica, situándose el nuestro como uno de los países con mayor sustentabilidad económica. Esta particularidad, sin embargo, no lo deja exento de conflictos. Es por esta razón que cada una de las problemáticas que se manifiestan como una contradicción a las normativas establecidas, en el contexto de su estructura social, serán comprendidas como incongruencias que deben ser resueltas para garantizar el orden de la sociedad. En este sentido, resulta pertinente abordar una manifestación de dicho conflicto, una temática que en los últimos años se ha convertido en una de las preocupaciones principales del gobierno con respecto a la gestión de nuevas políticas públicas: la delincuencia.

En efecto, el fenómeno de la delincuencia ha ido adquiriendo mayor importancia a nivel social en tanto el poder vivir en un ambiente seguro se ha posicionado como un factor relevante para el desarrollo integral de los ciudadanos, junto con aspectos que lo han sido históricamente como es la estabilidad económica y el área de la salud. Ejemplo de esto es el aumento de la sensación de inseguridad en la población durante los últimos años, lo que ha permitido que la delincuencia se establezca como una de las problemáticas más relevantes a nivel nacional. Según los datos entregados por el Instituto Nacional de Estadísticas sobre los resultados de la Encuesta Nacional Urbana de Seguridad del año 2008, el 19,98\% declara tener miedo de ser víctima de un delito.

Diversas han sido las posturas con respecto al origen de la delincuencia durante los últimos años, existiendo desde enfoques psicobiológicos, que comprenden la delincuencia como una anomalía o disfunción a nivel orgánico, y por ende anterior y al interior de cada individuo (Mednick, Gabrielli y Hutchings, 1984; C. Lombroso, 1897; R. Garofalo, 1896; W. Sheldon, 1949); hasta vertientes más sociológicas que explican la delincuencia desde factores multicausales (García-Pablos de Molina, 2003; Bynum y Thompson, 2007).

Entre estas últimas teorías se encuentra la de "socialización deficiente" (Quételet, 1970; Lacassagne, 1908), donde se explica la conducta criminal como una falla en el proceso de socialización, "ya sea por un defectuoso aprendizaje en la infancia o por imitar, asociarse o integrarse en diversos grupos o subculturas delincuentes" (González, 2003:9) por lo que el individuo se ve dificultado para llevar a cabo correctamente los conflictos normativos o de conducta.

Otra rama de las teorías sociológicas es planteada por la Escuela de Chicago, quienes estudian la criminalidad desde una perspectiva ecológica, donde ésta es relacionada con la estructura social y el ambiente en el que están insertos los individuos.

De estos planteamientos han derivado diversos estudios sobre los factores criminológicos que facilitan o propician las conductas delictuales. Así encontramos los estudios de E. Wells y J. Rankin (1991), quienes observaron la prevalencia de la delincuencia juvenil en hogares disfuncionales, siendo aún mayor en familias rotas por divorcio. Similares planteamientos tienen las teorías del aprendizaje (A. Bandura y R. Walters, 1988), donde resultan particularmente interesantes los 


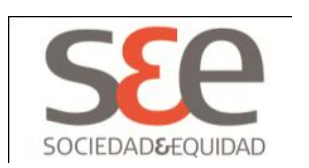

planteamientos de E. Sutherland en su teoría de la socialización diferencial o de los contactos diferenciales, en la que explica que el comportamiento desviado es aprendido en el contacto con un sistema donde priman los valores criminales, por lo que una persona "se vuelve delincuente o tendrá mayores posibilidades de delinquir cuando las actitudes positivas frente al comportamiento desviado superan cuantitativamente a los juicios negativos" (González, 2003:15).

Creemos que esta visión simplificada de la socialización transmitida por grupos criminales y no criminales como factores explicativos del comportamiento delictual, puede estar en la base del miedo, la segregación, sectorización y estigmatización a determinados grupos de la sociedad. Es en este aspecto que nos interesa indagar, ya que si nos abstraemos de buscar las causas inmediatas de la delincuencia para centrarnos en los procesos de interpretación y definición del comportamiento desviado, aparecen aspectos como la inseguridad, el miedo y el estigma asociados a dichas construcciones sociales que hacemos de un otro diferente.

En este contexto, el presente artículo busca analizar los procesos de interpretación y definición del comportamiento desviado y la inseguridad que éste ha instalado en los individuos de dos comunas especificas, para enfocarnos en el estigma o etiquetamiento que se construye como resultado de ello. Para efectuar éste análisis se abordaron dos comunas, Las Condes y Peñalolén. En esta última comuna resultó ser de gran importancia determinar claramente la dimensión territorial a abordar debido a la creciente diversificación de estratos sociales que se ha desarrollado en los últimos años, por lo que la muestra se acotó al sector de Lo Hermida y Villa Cousiño como representativos de los sectores populares.

Establecidas las comunas, la pregunta a responder en el presente artículo será ¿Cuales son las consecuencias de la relación que se establece entre habitantes de clase alta residente en Las Condes, frente a los habitantes de sectores populares de Peñalolén? Y por tanto el objetivo buscara explicar dichas consecuencias. Tomando como referencia dicha pregunta partiremos con el análisis del contexto, las diferencias concretas desde las cuales se construye la naturaleza social, las diferentes categorías de estratos sociales que acuña cada una de las comunas, y la problemática concreta de la delincuencia, ya que al establecerse una diferenciación entre ellas se da pie al establecimiento de un estigma entre clases mediante acciones concretas.

La técnica de investigación utilizada remite a un estudio de caso, donde las técnicas de recolección fueron la revisión bibliográfica, etnografía y entrevistas a habitantes de ambos barrios. De manera específica, la técnica de Entrevista agrupó tanto a habitantes de Las Condes como de Peñalolén, escogidos de manera aleatoria, pero procurando mantener equidad entre las distintas comunas en lo que refiere a rango etario y sexo, de este modo se garantiza una diversificación mayor de percepciones sobre la temática abordada.

En cuanto al marco teórico utilizado para analizar la información recolectada, éste se basa principalmente en un cruce entre las llamadas "teorías del etiquetamiento o de la reacción social", acuñando principalmente los planteamientos del sociólogo E. Goffman, y las "teorías de la estructura social defectuosa", específicamente la desarrollada por Merton. 


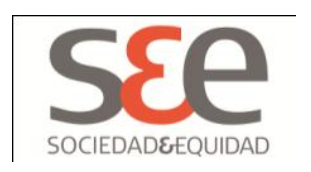

Para Goffman (2003) la sociedad tiene la necesidad de establecer los medios para categorizar a las personas, por lo que se difunden los atributos y normas corrientes y naturales que las personas de determinada categoría deben apoyar y llevar a cabo. Es así que existen las características en esencia, que refieren a las expectativas normativas que constituyen una identidad social virtual y las características reales o categorías y atributos que las personas poseen y que configuran su identidad social real. En este marco, el estigma aparece cuando hay un atributo que vuelve a alguien diferente de los demás y hace que dejemos de verlo como una persona total y corriente para reducirlo y desacreditarlo, elaborando una "ideología para explicar su inferioridad y dar cuenta del peligro que representa esa persona” (Goffman, 2003: 15).

Una conceptualización importante de rescatar en este momento es la idea de carrera moral, donde Goffman reconoce que las personas no sólo reciben un estigma pasivamente sino que también son socializadas con las mismas experiencias relativas a su condición y "por las mismas modificaciones en la concepción del yo" (Goffman, 2003:45), por lo que reproducen las creencias de lo que significa tener un estigma particular. Por tanto, el estigma se hará manifiesto cuando en una sociedad con una estructura normativa instalada, es decir, con valores y expectativas determinadas, se desarrollen discrepancias entre la identidad social virtual y la identidad social real, es decir, cuando se manifieste una contradicción entre las categorías y atributos que se otorgan a determinados grupos sociales y los atributos reales que posee cada sujeto perteneciente a dicho grupo social; lo que provocará una problemática que traerá consigo un daño en la identidad social de una persona y promoverá que esta sea desacreditada frente a un mundo que no lo acepta.

De este modo, se puede dar cuenta de una vinculación entre los fenómenos de delincuencia, inseguridad y estigmatización. El orden presentado resulta ser coherente para efectos del fenómeno en sí, y lleva a preguntarnos si sólo es la delincuencia la que genera una sensación de inseguridad que luego legitima un estigma, o bien luego de haber sido establecido, es el propio estigma el que provoca la inseguridad en sí misma, sin la necesidad de haber sido víctima de acciones vinculadas a la delincuencia.

Así, ciertos territorios comienzan a ser cargados de características negativas, conformándose de este modo los imaginarios sociales desde los cuales serán comprendidos, no sólo los territorios sino además los sujetos que allí habitan. Es por ello que se puede argumentar que el resultado del estigma, producto de la relación establecida entre las comunas mencionadas instala diversas formas de estigma que recaen no tan sólo en quienes han sido protagonistas de actos delictivos sino además en todo aquel que comparta su ubicación territorial, en este caso la comuna, convirtiendo a todos sus habitantes en potenciales delincuentes. Este hecho es replicado en cada uno de los sectores que se han sido instalados como las cunas y/o orígenes de la población criminal. 


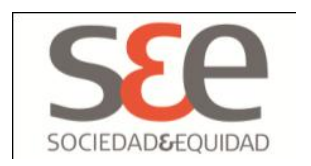

\section{El miedo y la seguridad ciudadana en el contexto nacional}

La realidad chilena ha experimentado en los últimos años un fuerte aumento en la delincuencia $y$, junto con ello, un aumento en la sensación de inseguridad percibida por los ciudadanos. Por ello no resulta extraño que la Encuesta Nacional Urbana de Seguridad, aplicada por el INE el año 2008, muestre como principales resultados dentro de las tres situaciones que a nivel personal generan mayor preocupación, respondan en primer lugar La Perdida de trabajo con un $27,9 \%$, seguido de Ser víctima de un delito con un $19,98 \%$ y finalmente de No contar con un sistema de salud que cubra enfermedades o accidentes. Pero además, resulta de suma importancia observar que cuando las personas son consultadas sobre la problemática que consideran mayormente relevante a nivel nacional se observe con un 19,98\% Ser víctima de un delito.

Lo anterior establece el nivel de importancia que ha ido adquiriendo el fenómeno de la delincuencia, instituyéndose como un factor igualmente relevante para el desarrollo integral de los ciudadanos, como lo ha sido históricamente la situación socioeconómica y el área salud. Es decir, hoy los individuos no sólo requieren de estabilidad económica, sino además de una importante sensación de seguridad que les permita un desarrollo integral. Dicha necesidad de seguridad queda plasmada en los estadísticos de la encuesta INE (Instituto Nacional de Estadísticas) 2008, donde se detalla el nivel de miedo establecido en diversos ámbitos de la vida de los ciudadanos. Es así como más del $50 \%$ declara sentirse Muy Inseguro (25.3\%) o Un poco inseguro (26.7\%) Caminando solo por su barrio cuando ya está oscuro. Situación que se repite al ser consultados por la sensación que poseen al esperar transporte público mientras esta oscuro, Muy inseguro (27.7\%) e Inseguro (26.2\%), mientras sólo un $8.9 \%$ declara sentirse Muy seguro en dicha situación.

Sin embargo, ya en la década de los noventa era posible dilucidar las posibles problemáticas que podrían gestarse en torno al fenómeno de la delincuencia; así lo plasmaban las investigaciones en torno a este fenómeno y que dejaban entrever la relevancia que iba adquiriendo. Doris Cooper (1994), en una investigación realizada plantea: "La delincuencia del gran Santiago es una delincuencia de tipo moderno (en términos comparativos del territorio nacional) caracterizada por concentrar los más altos porcentajes de delitos contra la propiedad, los que en 1992 alcanzan a un 90\% del total de los delitos" (Cooper, 1994: 47).

Ante este panorama es que los últimos gobiernos han enfatizado la Seguridad Ciudadana como mecanismo de protección contra este fenómeno que se ha transformado en una de las principales preocupaciones de los gobiernos regionales y locales que se han instalado en el poder en los últimos años. No obstante, es preciso aclarar que si bien la Seguridad Ciudadana se ha instalado como una temática relevante no solo a nivel nacional si no también latinoamericano, es porque requiere de un abordaje efectivo, pero al mismo tiempo responsable y minucioso.

Ahora bien, sumado al fenómeno concreto de la delincuencia, se ha observado un fuerte aumento en el nivel de violencia, provocando un desajuste en el tejido social de la ciudadanía, estableciendo mayor temor e impidiendo un desarrollo efectivo a nivel país. (Cooper: 1994) En este sentido, resultará necesario entender la delincuencia y la violencia que se ha instalado en ella, no sólo como 


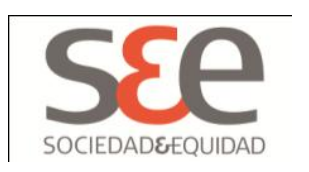

una causa, sino además como una consecuencia de múltiples problemas instalados en la sociedad, como es la falta de oportunidades, segregación socio-espacial y el desempleo, entre otras. Por tanto la sensación de miedo, "esa descarga es, en sí misma, una reacción utilitaria de legítima defensa, que sin embargo el individuo no siempre usa oportunamente. Al volverse colectivos, los temores pueden transformarse en pánicos" (Delumeau, 2002: 14).

Sin pretender pasar por alto una realidad constatable y justificable mediante los datos presentados por diversas instituciones a nivel nacional con respecto al fenómeno de la delincuencia, es posible ver cómo de dicho fenómeno se han desprendido otros que merecen ser abordados con el mismo nivel de importancia, como es el caso de la estigmatización de barrios populares. Por ello se hace necesario realizar el ejercicio diferenciador entre la realidad que a nivel nacional nos permite observar el creciente fenómeno de temor, frente a los datos concretos de violencia presentados en la región, debido a que es en ella donde se observa la diferencia entre los niveles representativos de la delincuencia y aquellos que reflejan el nivel de temor. Nuestro país, por ejemplo, se caracteriza por poseer mayores niveles de Temor que de delincuencia. Dicha realidad ha sido plasmada por diferentes estudios a nivel nacional, en el caso de los estadísticos presentados en el 2008 por el INE (Instituto Nacional de Estadísticas) donde se constata que el $66.5 \%$ de los ciudadanos declara No haber sido víctima de algún delito, sin embargo al minuto de ser consultados por los niveles de seguridad que perciben ante situaciones de riesgo, más del 50\% declara sentirse Muy Inseguro o Inseguro.

Por ello reiteramos la necesidad de no encasillar la delincuencia y la violencia con la que ésta se ha instalado sólo como una causa de la creciente sensación de inseguridad de los habitantes, sino además como la consecuencia de múltiples problemáticas sociales.

\section{Contexto de Peñalolén y Las Condes como comunas a ser abordadas}

\section{Peñalolén}

La comuna de Peñalolén se encuentra ubicada en el sector oriente de Santiago, limitando con cinco comunas, La Reina, Las Condes, Ñuñoa y Macul. Posee una superficie de 54,8mt2 y es considerada como una comuna heterogénea por albergar a personas de todos los estratos sociales. Pero a pesar de su heterogeneidad, se ha caracterizado por una fuerte cantidad de población perteneciente a estratos sociales más bien bajos, barrios como Lo Hermida originados producto de una toma de terreno, y Villa Cousiño son característicos de ella. Según los datos entregados en el censo del año 2002 Peñalolén posee 216.060 habitantes, siendo considerada por ello como una comuna Populosa. 


\section{S\&e \\ SOCIEDADEEQUIDAD}

Figura 1

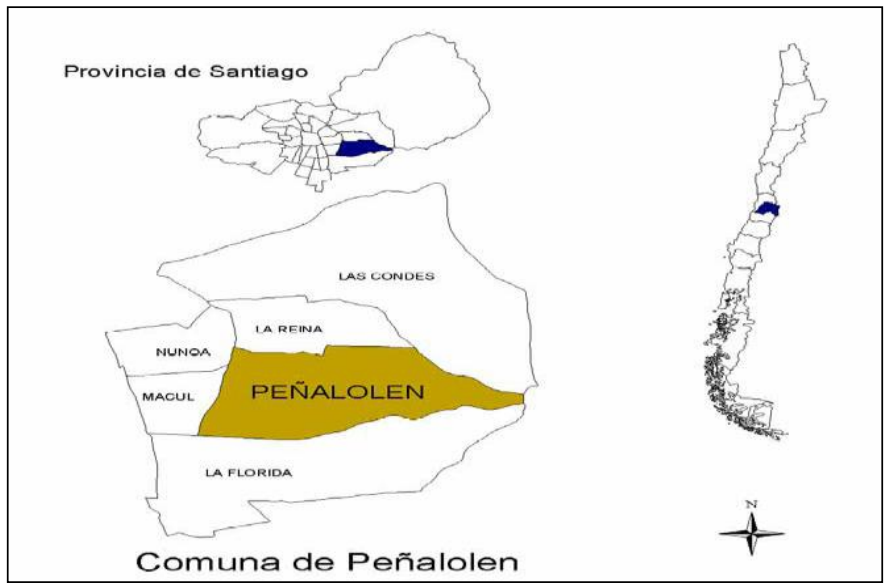

FUENTE: PLADECO Peñalolén (2006), Plan de Desarrollo Comunal.

\section{$\underline{\text { Las Condes }}$}

La comuna de Las Condes se encuentra ubicada en el sector oriente de la ciudad de Santiago, y se ha caracterizado históricamente por albergar mayoritariamente a una población de clase media alta y alta. Con una superficie de 99.4 km2, Las Condes limita con las comunas de Peñalolén, Vitacura, Lo Barnechea y Providencia. Según el censo 2002 su población llega a 249.893 habitantes.

\section{Figura 2}

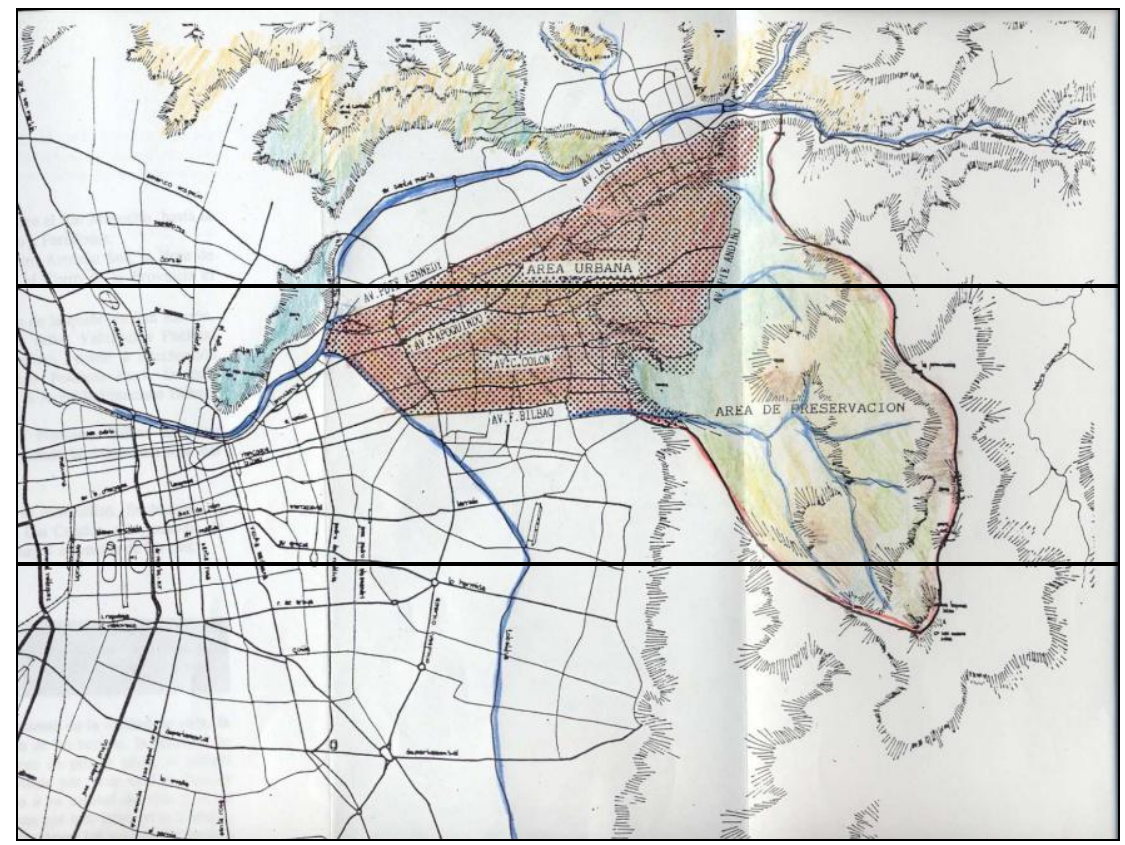

FUENTE: PLADECO Las Condes (2010 - 2013) Plan de desarrollo Comuna. 


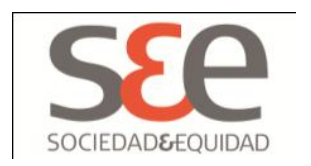

\section{Estigma y Anomia como conceptos centrales en la realidad actual}

Han sido muchos los teóricos que han abordado temáticas relacionadas con las diversas incompatibilidades manifestadas en las estructuras de la sociedad. Así, encontramos autores como Merton y Goffman que aún siendo representantes de vertientes sociológicas distintas, como son el estructural funcionalismo y el interaccionismo simbólico respectivamente, desde sus análisis es posible abordar una misma problemática.

Por una parte, Merton comprende que las diversas dimensiones establecidas en la sociedad resultan interdependientes entre sí, y que, por tanto, si uno de dichos aspectos se viese modificado, ello traerá consecuencias al resto de la estructura. Por su parte, Goffman, ha hecho hincapié en los fenómenos microsociales, es decir, en las interacciones entre los sujetos de la sociedad, poniendo énfasis en los elementos simbólicos que dichas relaciones conllevan. En este contexto, los conceptos de anomia en Merton, y el estigma en Goffman, resulta ser un punto en el que los dos autores logran encontrarse. Esto implica que aún cuando Goffman ponga énfasis en fenómenos microsociales generados en la sociedad, estos se verán influidos por las estructuras sociales que, a su vez, se ven afectadas por las interacciones.

El concepto de Anomia en Merton se entiende como "un síntoma de disociación entre las aspiraciones culturalmente prescritas y los caminos socialmente estructurales para llegar a dichas aspiraciones" (Merton, 1970:143), mientras que el estigma en Goffman será definido como "... mal en sí mismo y no a sus manifestaciones corporales." (Goffman, 2003:11). De esta forma, resultará pertinente abordar la temática del estigma establecido en la estructura social no sólo como una manifestación de las relaciones interpersonales desarrolladas entre sujetos, sino más bien como el resultado de diversas estructuras sociales, cargadas de una moral y valores determinados que aportan a la construcción de las normativas desde las cuales se rige la sociedad. En suma, tanto la anomia como el estigma son resultado de dichos establecimientos normativos, por tanto sus manifestaciones en la sociedad resultan ser el reflejo de las incongruencias que pueden surgir a partir del establecimiento del orden social.

\section{Construcción de un estigma social establecido en sociedad}

La distribución espacial en la ciudad es un proceso en constante cambio, lo que va acompañado del establecimiento de diversos imaginarios sociales, donde se identifican ciertos lugares de la ciudad, estratos sociales y por tanto estructuras sociales determinadas. En Chile, uno de los casos más emblemáticos se observa en la comuna de Las Condes, comprendida socialmente como una comuna representativa de estratos sociales altos, "Tu entras a un barrio de Las Condes y hay casas de segundo, tercer piso, de hecho son materiales a veces...mucho más caros" (Joven 21 años, Peñalolén). Mientras otras comunas como La Pintana, Peñalolén, entre otras, han agrupado a estratos sociales más bajos "aquí en Peñalolén los ingresos son escasos" (Joven 21 años, Peñalolén). 


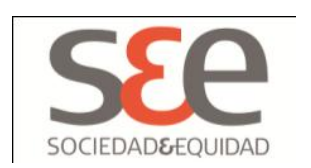

Por lo que al seleccionar estas dos comunas permite la observación representativa de una estratificación no sólo territorial sino también económica y social en la ciudad de Santiago.

Estos fenómenos no hacen más que responder a una realidad social generalizada, que se ha caracterizado desde comienzos de la modernidad por establecer nuevos valores y modelos a seguir que determinan las expectativas de vida de los individuos, pero, no así las condiciones para ello.

Pero fuera de la imagen construida a nivel social sobre estos sujetos, resulta de vital importancia comprender la forma desde la cual se perciben los propios actores. En el caso de los habitantes de Las Condes más que considerarse como parte de un formato de vida que los caracterice, consideran que son las condiciones económicas o externas las que les permiten establecerse territorialmente en un lugar, pero que ello no necesariamente determina patrones de comportamiento en común entre ellos

No, la verdad es que no aprecio una característica, una actitud particular que pueda decir, esta es gente de Las Condes, salvo los que se distingue por su, por su forma de hablar y por su... por ostentar lo que tiene...

(Hombre 52 años, Las Condes)

Sin embargo, reconocen la diferencia en cuanto al nivel de vida al cual pueden acceder en comparación con estratos sociales más bajos, y que dicha condición muchas veces hace que ciertos habitantes actúen estableciendo una diferencia entre ellos y los otros.

... porque ya saben que con una educación mas privada, ya optai' por una, no porque te pasan la materia mejor o no, sino en la calidad de gente que hay, porque la gente que tiene como más dinero, obviamente te da más seguridad, obviamente en los colegios hay de todo, en otros no, por ejemplo te hacen pasar una prueba de actitud, y si no pasas el seis no entrai', entonces por eso la gente opta.

(Mujer 18 años. Las Condes)

Por otra parte, al referirse los habitantes de la comuna de Las Condes a los habitantes de Peñalolén, ponen énfasis en dos características fundamentales y que coinciden con la imagen social generalizada en los diversos medios de comunicación. La primera dice relación con el carácter de sacrificio que poseen dichas personas ante la vida, considerando que las condiciones económicas en que viven requieren de mayor esfuerzo, pero además se manifiesta casi inevitable la imagen del llamado flyte, personaje característico de las zonas populares y/o marginales de la ciudad de Santiago, que al carecer de un nivel educacional mínimo adoptan nuevas formas de comunicación y comportamiento, que les permite identificarse, pero que se encuentra alejado del lenguaje formal. 


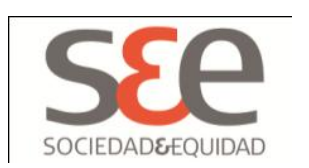

En la construcción de este imaginario social nace una interrogante, ¿será que en ella sólo se considera una imagen caricaturesca de un grupo determinado de individuos sin desarrollar consecuencia alguna, o ello hace alusión a condiciones concretas que se observan como resultado de dicha caracterización? Y aun cuando desde la perspectiva de los habitantes de territorios de estatus socioeconómico alto, los sujetos de sectores populares de Peñalolén no son catalogados como buenas o malas personas, igualmente son comprendidos como diferentes.

De este modo, se otorga a los individuos ciertos atributos socialmente desvalorizados, que al ser asociados los espacios físicos y estratos socioeconómicos determinados, construyen y cargan con un estigma a quienes habiten en dicha comuna.

...porque la gente que tiene como más dinero, obviamente te da más seguridad.

(Mujer 18 años. Las Condes)

En el caso puntual de las condiciones sociales relacionadas con una realidad en la que se originan muchos focos de delincuencia, el estigma va ligado a rasgos del lenguaje y características que denoten las costumbres y los gustos de los sujetos.

Volviendo al punto principal de interés en Goffman, al establecer el foco de análisis en los contactos mixtos, el análisis se sitúa en el encuentro entre el o los Normales, en este caso los habitantes de Las Condes como representantes de los estratos sociales altos y los Estigmatizados, sujetos de la comuna de Peñalolén que forman parte de un estrato socioeconómico medio, medio bajo y que poseen como principal característica de estigma el vivir en un territorio en el que históricamente se han dado las condiciones para albergar a sujetos que delinquen en barrios del sector oriente.

Mira, los orígenes de la delincuencia que viene para acá es multisectorial, viene de Peñalolén, viene del sector norte, viene de La Pintana, viene de Maipú, de todas partes. Si tú me preguntas de donde se repiten más, se me repiten más de Peñalolén.

\section{(Especialista en Seguridad Ciudadana)}

De esta forma, el encuentro directo entre Normales y Estigmatizados se da en el ejercicio mismo de la delincuencia. Pero el estigma no se limita a ello, ya que es en base a esa situación que se establecen los imaginarios sociales no sólo con respecto al sujeto que ha transgredido la norma, pasando a llevar la integridad personal de otros sujetos, sino un conjunto de características negativas con las cuales carga el delincuente, que tienen relación con un conjunto de normas y valores que forman parte de su propio, mundo establecido en territorios determinados.

En este sentido se produce una extensión del estigma, una generalización casi inconsciente de que quienes están dentro de un contexto con similares características al de los delincuentes, o anormales, se encontrarán en condiciones similares a éste, por lo que se convierten en potenciales delincuentes. 


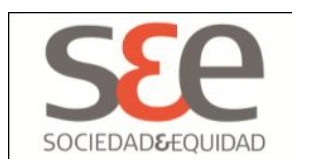

Por otro lado, los habitantes de la comuna de Peñalolén, plantean que en Peñalolén los ingresos son escasos. $Y$ al momento de plantear su percepción en términos comparativos con respecto a los sujetos de la comuna de Las Condes plantean que:

Los colegios son distintos, diferentes estructuras, diferentes cosas que te enseñan, las materias, la enfocan en otro punto de vista, o simplemente pasan más materia.

(Mujer 18 años, Peñalolén)

Si bien cabe mencionar que el contexto social y cultural al cual se ven enfrentados los sujetos de las poblaciones abordadas, Lo Hermida y Villa Cousiño remiten a una realidad que, aun cuando en estricto rigor no forman parte de los sectores más precarios de la ciudad, se observa una realidad carente de calidad necesaria en sus instituciones primarias para permitirles enfrentarse en igualdad de condiciones a los distintos ámbitos de la sociedad.

Tú vas caminando por la calle y no ves tanta cantidad de árboles, y eso ya es una cosa que denota.

(Joven, 19 años, Peñalolén)

Comunas como Peñalolén, La Ligua, o cosas así a la gente se le dan menos oportunidades, porque, porque obviamente tienen sueldos más bajos, y a los niños se les tira a colegios que son municipales, en cambio lo que es en sectores como Las Condes, casi no existen colegios municipales.

(Hombre 21 años, Peñalolén)

Se comprueba entonces, que los sujetos de Peñalolén se observan a sí mismos principalmente como un segmento que ha debido mantenerse mediante condiciones que muchas veces no resultan ser favorables para su desarrollo integral, pero además de dicha precarización en las condiciones, remiten principalmente a un descuido histórico por parte de las instituciones gubernamentales existentes para garantizar el bienestar social.

Sin embargo, lo que resulta más relevante en términos de análisis son las observaciones que hacen sobre la situación de seguridad y delincuencia, ya que se manifiesta el mismo nivel de preocupación tanto por la situación objetiva de inseguridad instalada en sus barrios debido al aumento de la delincuencia, pero además sobre las condiciones sociales, culturales y educacionales que aportan a la insatisfacción que se ha instalado. 


\section{SSe}

Cuando a uno le roban, es porque necesitan algo, necesitan dinero, si nos vamos a un barrio como las condes, pocas personas o sea no te van a querer asaltar así como así en la calle. A menos que personas de Peñalolén vayan a asaltar a barrios de Las Condes, porque obviamente ellos saben que tienen más plata.

(Hombre, 21 años, Peñalolén)

De este modo resulta doblemente interesante abordar la forma en que los habitantes de Peñalolén se observan a sí mismos como un segmento de clase social media baja, donde resulta imprescindible la relación recíproca entre vecinos, debido a las circunstancias socioeconómicas que los caracterizan, y la relevancia otorgada en sus discursos al modo de identificarse, ya que todos sus discursos nacen de la dualidad existente con otros que poseen lo que ellos requieren para su bienestar.

...Cuando dicen Chile desarrollado, tú ves Las Condes y claro, eso es lo que muestran, Las Condes, no muestran otros barrios que son más brigidos donde la gente es pobre, donde la gente no tiene educación, donde hay más delincuencia, donde hay más drogas y no se po'... y narcotráfico...

(Mujer 18 años, Peñalolén)

\section{El proceso de socialización en la construcción de una figura en la sociedad}

De este modo los individuos adquieren en sociedad no sólo los objetivos a los cuales deben aspirar, sino además las formas de comportamiento social y moral que les garanticen formar parte de ella (Merton: 1970). La seguridad por ejemplo, a raíz de la creciente sensación de inseguridad provocada por la delincuencia, se ha convertido en uno de los comportamientos sociales más relevantes a nivel social, cuestionándose todo acto que irrespete dicha normativa.

En seguridad obviamente ellos demandan, y esa es la lucha de nosotros, tener una sensación de seguridad aceptable, o sea, ellos demandan estar tranquilos.

(Especialista en Seguridad Ciudadana)

Pero no será solo la adaptación a las normas lo que permitirá a un sujeto ser parte de un colectivo sino además el poder demostrar a un otro la capacidad de obtención de los medios necesarios para ello "Las sociedades como la nuestra pues, la gran importancia cultural dada al éxito pecuniario para todo..." (Merton, 1970: 158). 


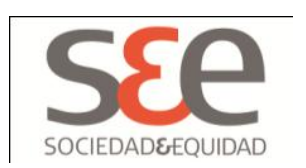

Todo ello ha elevado las expectativas de los sujetos sin diferencia de raza, clase, o lugar. Es el conjunto social total, el que busca obtener siempre los mejores resultados con el objetivo de ser aceptado y de lograr la satisfacción personal.

La gente no roba por necesidad, siempre están robando el iphone, siempre están robando la cámara...

(Joven 18 años, Las Condes)

Dichas expectativas no resultarían negativas de manera alguna si ellas no hubiesen dejado de manifiesto las dificultades e incongruencias que ello trae consigo, ya que si bien la posesión de expectativas resultó expandirse de manera homóloga, fue la distribución y materialización de estos lo que resultó muy distinto entre los sujetos, "... y una estructura social que limita en forma indebida la posibilidad de recurrir prácticamente a medios aprobados, producen en muchos una tensión hacia prácticas innovadoras que se apartan de las normas institucionales." (Merton, 1970: 158). Asimismo lo plantean los habitantes de Peñalolén:

...yo creo que si una persona nace acá, aprende todo lo de acá, no lo pueden culpar no se po', de ser flayte ponte tu, como podi' culpar a una persona si en su vida no vio más que eso.

(Mujer 18 años, Peñalolén)

Haciendo alusión principalmente al contexto social en el que se desenvuelven y desarrollan los sujetos pertenecientes a las poblaciones más vulnerables de Peñalolén, se explicaría por sí mismo la búsqueda constante por responder a las expectativas sociales, pero no así, a los medios socialmente aceptados para ello.

Varios factores, la plata, la drogadicción que los lleva a hacer eso, y a veces también parte de los más cercanos, porque también hay cabros chicos que andan asaltando, y eso fue, el comienzo de eso fue porque otro amigo lo invitó a salir simplemente, eso pasa y ha pasado, el cisarro por ejemplo y sus amigos, cuando fueron a asaltar sus amigos, el loquin, lo invitaron a asaltar y así comenzó todo.

(Mujer, 18 años Peñalolén)

De este modo, así como un bebe aprende mediante la reproducción de lenguaje, gesto y pensamiento que le otorga un adulto, los sujetos aprenderán buscando reproducir prácticas y comportamientos que los grupos de sujetos Modelo desarrollen en su diario vivir. Con ello se observa el fenómeno planteado anteriormente, y es que independiente de la naturaleza de los individuos de la sociedad, siempre guiaran sus acciones en función de las mismas expectativas. En definitiva, y en el 


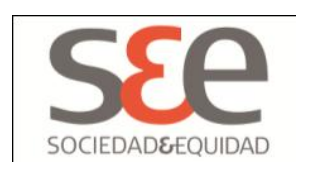

caso de nuestro país, se podría decir que la clase alta se ha establecido como un ideal a seguir por su capacidad adquisitiva como grupo de referencia, pero en términos prácticos al no poder entregar dichos beneficios a todos los ciudadanos, es decir, no lograr la obtención de los bienes necesarios para cumplir con las expectativas, salen a la luz las diferencias, dejando entrever los conflictos.

\section{Consecuencias de funcionamiento del estigma}

Como se pudo identificar, el estigma se materializa en la percepción que tiene un grupo de habitantes con respecto a otro, en este caso establecidos mediante estratos sociales objetivados en clases sociales que se ubican territorialmente al interior de la comuna de Santiago. Ello dará como resultado la manifestación de dos perspectivas desde las cuales se origina y desarrolla el estigma.

\section{Figura 3}

\section{Consecuencias del Estigma}

\begin{tabular}{|c|c|c|}
\hline Comuna & $\begin{array}{c}\text { Consecuencia de la sensación de } \\
\text { Inseguridad. }\end{array}$ & $\begin{array}{c}\text { Resultado objetivo en la realidad } \\
\text { social. }\end{array}$ \\
\hline Las Condes $\longrightarrow$ & Miedo $\longrightarrow$ & Búsqueda de seguridad \\
\hline Peñalolén $\longrightarrow$ & Estigma $\longrightarrow$ & Barreras sociales \\
\hline
\end{tabular}

Elaboración Propia.

De este modo se objetivan las consecuencias del estigma, según la perspectiva de los habitantes comprendidos como Normales y Estigmatizados.

En suma, se comprende que la sensación de inseguridad traerá consigo consecuencias no sólo para quienes han sido víctimas de una situación que involucre riesgo e inseguridad, en este caso en los habitantes de Las Condes, sino además en quienes forman parte de un contexto compuesto por un alto índice de vulnerabilidad social, como resulta ser el caso de los sectores populares de Peñalolén.

No discrimino, lo que sí, la llegada del metro, y el transantiago, nos pusieron un paradero acá, eso hace transitar más gente y eso hace que... puedan estar mirando casas... y se ha notado porque han empezado a aparecer las famosas marcas de pintura en las casas. (Hombre 52 años, Las Condes)

La diferencia de dicha sensación resultará importante, ya que en una de ellas se establecerá el miedo como principal consecuencia, lo que lleva a sus integrantes y autoridades a buscar mecanismos específicos que otorguen la garantía necesaria para resguardar dicha situación. 


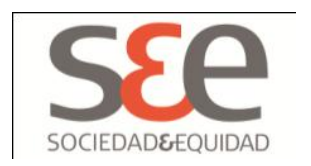

Nosotros cubrimos, nuestra comuna la tenemos geográficamente dividida en trece cuadrantes... a lo menos va a ir un funcionario a cada uno de los trece cuadrantes, si tenemos más medios irán funcionarios a los cuadrantes más conflictivos, a las cuadriculas de ese cuadrante...

(Especialista en Seguridad Ciudadana)

Por el contrario, en la comuna de Peñalolén, lo que se manifiesta como consecuencia será más bien un proceso de categorización negativa o estigma que recaerá en sus integrantes, lo que bloquea la posibilidad inmediata de remediar dicha situación, estableciendo, de este modo, barreras sociales que se manifestaran en diversas áreas de la sociedad.

Uno de los casos de delincuencia más recientes fue el que tuvo como protagonista al Cisarro, niño que a muy corta edad infringió la ley, llevando a cabo diversos asaltos con un alto grado de violencia. A raíz de este caso se abrió el debate sobre la delincuencia y la intervención efectiva de SENAME (Servicio Nacional de Menores) en casos como estos. Pero junto a ello, se fue potenciando el estigma a la población a la cual él pertenece, Villa Causiño, Peñalolén.

Eso también te afecta en tu vida porque si tu vay a buscar pega y digo que soy de Peñalolén, al lado del cisarro, no me aceptan nica, ni si quiera me miran, te dicen te vamos a llamar y no me aceptan en la pega.

(Joven 21 años, Peñalolén)

Yo creo que en un punto la gente lo ve mal, por lo menos de barrios más altos si...

(Joven 21 años, Peñalolén)

Por tanto, para los habitantes de la comuna de Las Condes, la delincuencia funciona como una acción conflictiva, que los enfrenta a una situación en donde lo que prevalece son los valores de Normalidad que deben ser resguardados, y ello justifica la búsqueda constante por la seguridad. Por otro lado, la perspectiva establecida por los ciudadanos de Peñalolén con respecto al mismo fenómeno tiene relación con un miedo por los cambios que a nivel social pudiesen provocarse, y apuntan principalmente al estigma construido en base a ello y las consecuencias que esto trae, es decir, las barreras sociales que un fenómeno como la delincuencia construye.

En suma, la construcción del estigma, nacido de la relación entre dos estratos sociales diferentes, se materializa en los dos contextos abordados, pero la diferencia práctica que en ellas se observa remite a la calidad de Prestigio que otorga a los habitantes de clase alta, estableciéndolos como el modelo a seguir o Grupo de Referencia (Goffman 2003), siendo dicho fenómeno potenciado constantemente por la labor ejercida en los medios de comunicación masivos. Otra consecuencia del estigma en este caso, resulta ser, por tanto, de carácter positivo, mientras que en Peñalolén, por resultar 


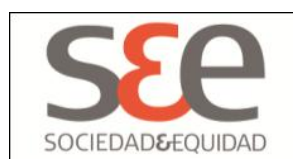

desacreditados debido a las cargas negativas que se les han otorgado, mantendrá el carácter negativo del estigma, limitando sus posibilidades objetivas en los diferentes ámbitos de la vida social, dejando entrever la problemática concreta causada por dichas interacciones.

\section{Figura 4}

\section{Mecanismos del estigma}

\begin{tabular}{|c|c|c|}
\hline Comuna & Símbolos del estigma & Resultado objetivo \\
\hline & & \\
\hline Las condes $\longrightarrow$ & símbolos de prestigio $\longrightarrow$ & Estigma positivo \\
\hline Peñalolén $\longrightarrow$ & Estigma $\longrightarrow$ & Estigma negativo \\
\hline
\end{tabular}

Elaboración Propia.

Sumado a lo anterior, se observa mediante el presente esquema que para efectos de la manifestación del estigma, ya sea con carácter positivo o negativo, éste precisará de manifestaciones concretas en la sociedad, como son los símbolos de prestigio en el caso de quienes resulten ser los así denominados Normales y el propio estigma en los estigmatizados o desacreditados.

De esta forma, el fenómeno del estigma se ha instalado en la sociedad más que como un fenómeno nuevo, como la naturalización de una realidad que al parecer forma parte del funcionamiento de la sociedad. Las relaciones interpersonales de la sociedad vienen cargadas de diferenciación y roles para efectos de mantener el orden normativo establecido, y los diferentes grupos sociales reproducen dichos modelos, lo que progresivamente va deteriorando la identidad de quienes no formen parte de dicho modelo a seguir.

\section{Conclusiones actuales del estudio y posibilidades futuras}

El estigma establecido entre clases sociales, en este caso el representado como resultado de la relación entre los habitantes de Las Condes y del sector popular de Peñalolén, resulta ser en principio una consecuencia de la sensación de inseguridad establecida en la ciudadanía debido al creciente fenómeno de delincuencia en la ciudad. De este modo, el estigma no vendrá dado sólo por la diferenciación territorial y económica presente en cada una de estas realidades, sino además por la diferencia en cuanto al imaginario que los sujetos hayan construido de un otro.

A pesar de ello, resulta importante destacar que dichas diferenciaciones se llevan a cabo de formas casi inconscientes, o más bien desde una perspectiva tan naturalizada que no permite a los sujetos 


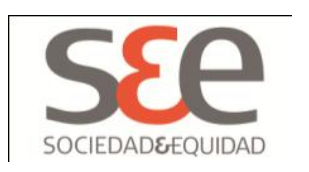

notar el carácter diferenciador de sus actos. El miedo a lo diferente, en este contexto, en realidad da cuenta de la evitación con un otro que no cumpla con las expectativas socialmente aceptadas.

En consecuencia, estamos frente a un proceso de configuración de un nuevo fenómeno social que establece en los sujetos un nuevo valor, que, en términos prácticos los lleva a rechazar la discriminación social. De este modo estarían en decadencia las visiones más drásticas que hasta hace algunos años era posible observar, pero aún cuando en sus discursos prevalece esta visión, en términos concretos sus acciones deben seguir vinculadas al acto diferenciador necesario para la configuración y mantención del orden social.

Es por ello que la delincuencia se ha transformado en un acto objetivo a rechazar en sociedad, ya que mediante este acto se transgreden las normas socialmente aceptadas, sólo que independiente de ello, al quedar inconclusas las explicaciones de dichos actos, se mantiene un vacio que da pie a la construcción de fenómenos como la estigmatización.

Parece ser que mientras los actos delictuales no se observen como una incongruencia entre los valores socialmente establecidos y las expectativas sociales de los individuos, y el estigma no se comprenda en sociedad como un fenómeno en sí mismo, dicho contexto seguirá su curso de modo continuo, ya que la solución ante esta realidad, depende para su modificación de múltiples factores, entre ellos uno de los más complejos, el funcionamiento de la estructura social.

En tanto, puede comenzar a abordarse un fenómeno que dice relación con el proceso constitutivo del estigma abordado en el presente artículo, y que merece ser desarrollado de manera más exhaustiva. Ello refiere precisamente al cuestionamiento del proceso de construcción y mantenimiento del estigma, ya que este deviene de una problemática social concreta, como es la delincuencia, la cual desarrolla un alto nivel de inseguridad, que finalmente sustenta el estigma. Pero tal vez esta sea sólo la relación inicial de dicho fenómeno, ya que pareciera ser que para el mantenimiento de esta situación, resulta ser el estigma por si sólo el que sustenta la inseguridad en los ciudadanos.

Las interacciones que configuran un estigma, por tanto, establecen un conflicto permanente entre los actores involucrados en dicha interacción, enfrentándose por un lado un estrato social que lucha por garantizar un orden social basado en la seguridad, y por otro lado, a quienes dicha búsqueda de seguridad los ha convertido en la permanente amenaza del orden. Por ello resultaría interesante para efectos de futuros estudios preguntarnos ¿Cómo afecta el funcionamiento concreto del estigma en la Identidad Social de los individuos? Comprendiendo que el estigma no solo limita el accionar físico, sino también social y cultural de los sujetos. 


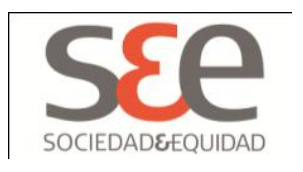

\section{Referencias Bibliográficas}

Cooper Mayr Doris (1994) Delincuencia común en Chile. Santiago: LOM.

Delumeau, M. T., Giraldo, J., Grimson, A., Lechner, N., Alvares, S., Niño, S., Echavarria, J., Sanchez, L.A., Riaño, P., Villa, I.P., Jaramillo, A. El miedo, reflexiones sobre su dimensión social y cultural. Disponible desde Internet en http://bibliotecavirtual.clacso.org.ar/ar/libros/region/reflexiones.pdf.

Goffman, E (2003) Estigma: la identidad deteriorada / Erving Goffman; traducido por Leonor Guinsberg. Buenos Aires: Amorrortu.

Merton Robert King (1970) Teoría y estructuras sociales. Mexicgo DF: Fondo de cultura económica.

Municipalidad de Las Condes http://www.lascondes.cl/ [Consultad en Agosto-Diciembre 2010]

Municipalidad de Peñalolén http://www.penalolen.cl/ [Consultado en Agosto-Diciembre 2010].

PLADECO Peñalolén (2006) Plan de Desarrollo Comunal. Disponible desde Internet en http://www.penalolen.cl/fileadmin/Documentos/PLADECO.pdf. [Consultado en Agosto-Diciembre 2010]

PLADECO Las Condes (2010-2013) Plan de desarrollo Comunal. Disponible desde Internen en http://www.lascondes.cl/interiores/ley.transparencia/plan.desarrollo.comunal/plan.desarrollo.comu nal.2010.pdf [Consultado en Agosto 2010-Diciembre 2010]

Vázquez, Carlos (2003) Delincuencia juvenil. Consideraciones penales y criminologías. Madrid: Colex. 


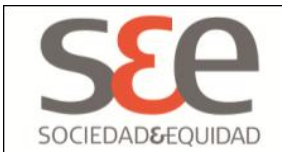

Figura 1

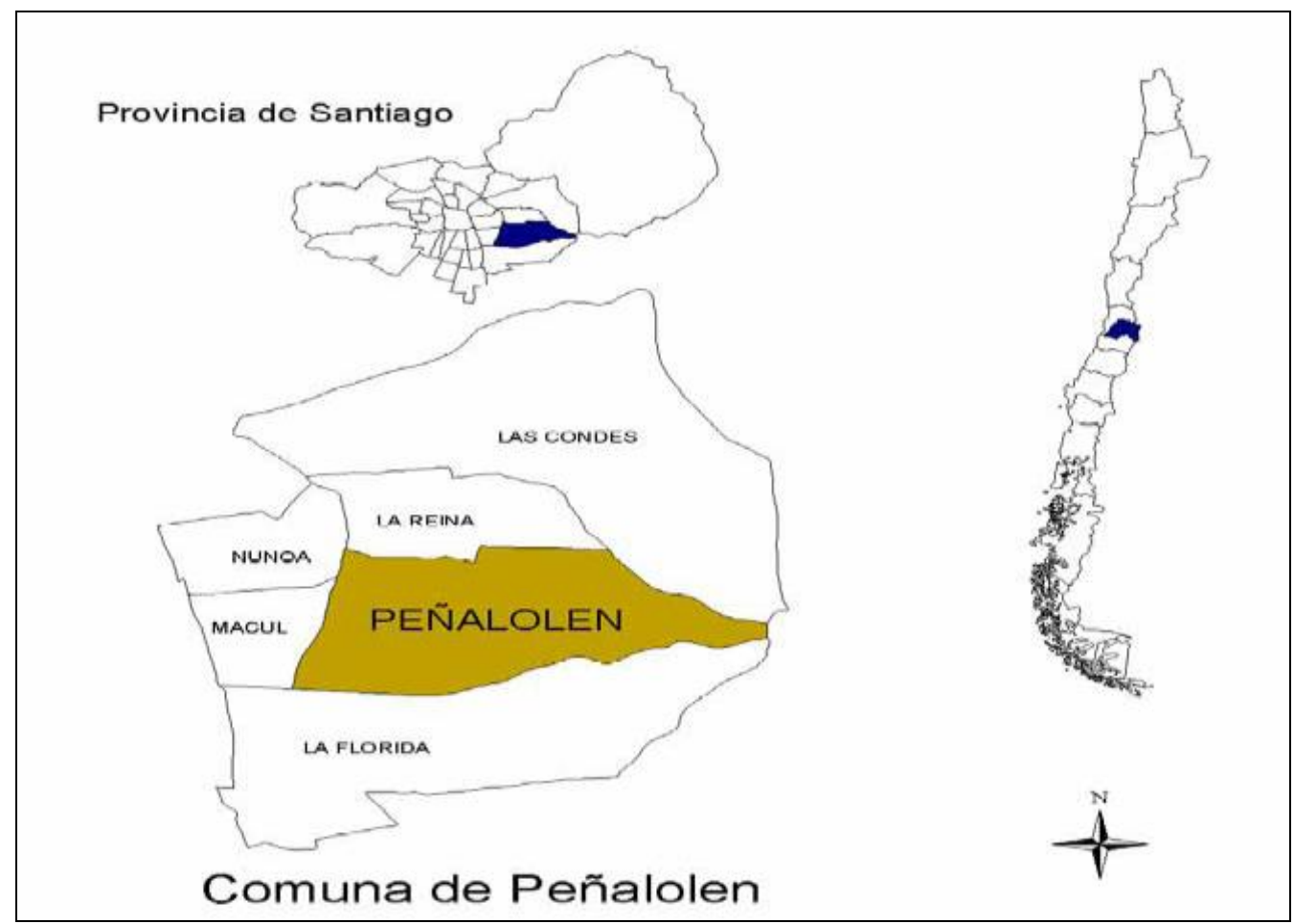

PLADECO Peñalolén (2006), Plan de Desarrollo Comunal. Disponible en:

http://www.penalolen.cl/fileadmin/Documentos/PLADECO.pdf. [Consultado Agosto - Diciembre 2010 


\section{SEe \\ SOCIEDADEEQUIDAD}

Figura 2

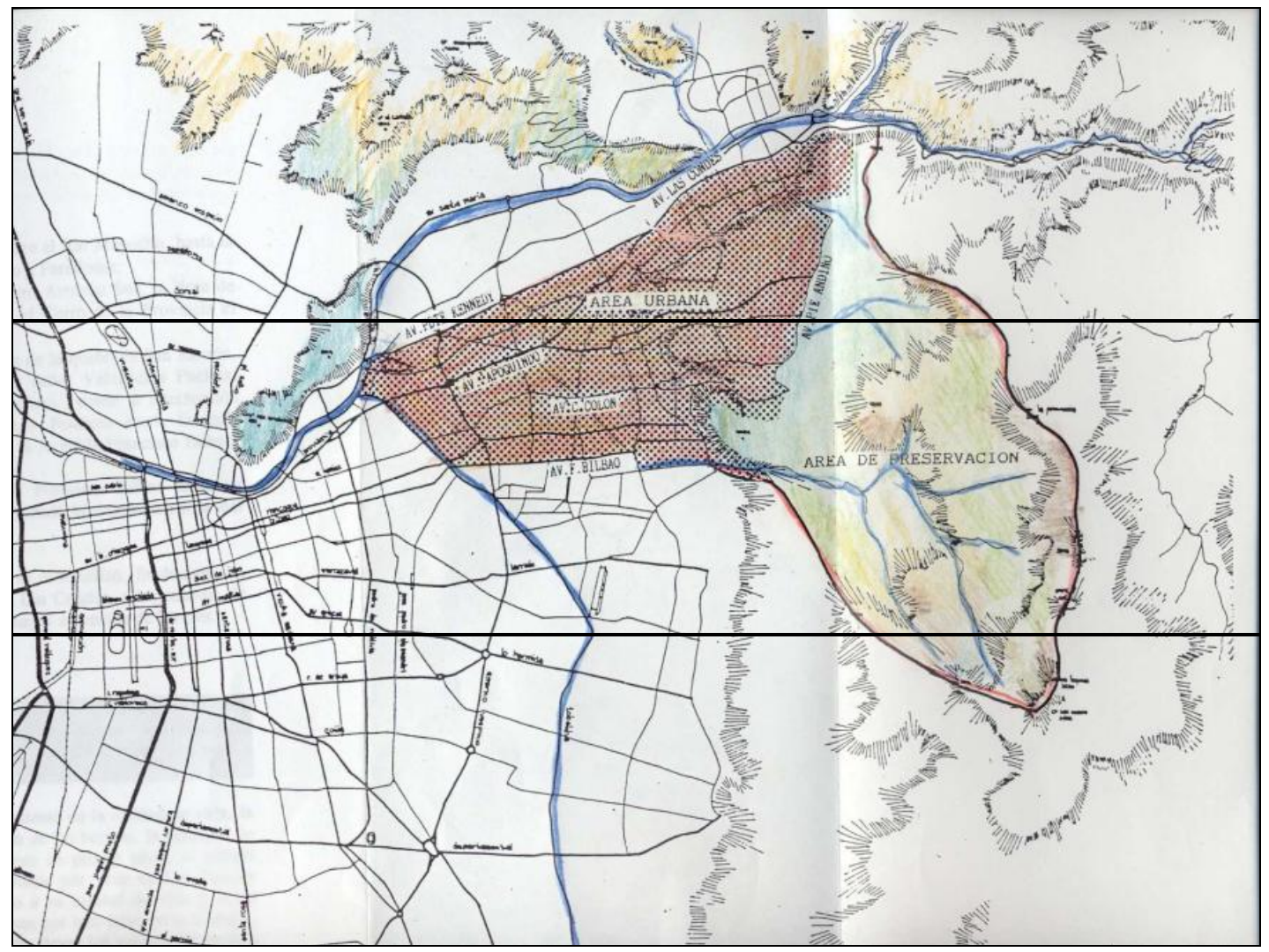

PLADECO Las Condes (2010 - 2013) Plan de desarrollo Comuna. Disponible en:

http://www.lascondes.cl/interiores/ley.transparencia/plan.desarrollo.comunal/plan.desarrollo.comu nal.2010.pdf [Consultado Agosto 2010 - Diciembre 2010) 


\section{sfe \\ SOCIEDADEEQUIDAD}

\section{Figura 3}

Consecuencias del Estigma

\begin{tabular}{|c|c|c|}
\hline Comuna & $\begin{array}{c}\text { Consecuencia de la sensación de } \\
\text { Inseguridad. }\end{array}$ & $\begin{array}{c}\text { Resultado objetivo en la realidad } \\
\text { social. }\end{array}$ \\
\hline Las Condes $\longrightarrow$ & Miedo $\longrightarrow$ & Búsqueda de seguridad \\
\hline Peñalolén $\longrightarrow$ & Estigma $\longrightarrow$ & Barreras sociales \\
\hline
\end{tabular}

Elaboración Propia.

\section{Figura 4}

Mecanismos del estigma

\begin{tabular}{|c|c|c|}
\hline Comuna & Símbolos del estigma & Resultado objetivo \\
\hline Las condes $\longrightarrow$ & símbolos de prestigio $\longrightarrow$ & Estigma positivo \\
\hline Peñalolén $\longrightarrow$ & & \\
\hline & Estigma $\longrightarrow$ & Estigma negativo \\
\hline
\end{tabular}

Elaboración Propia. 